Final Report

FHWA/IN/JTRP-2009/3

\title{
INVESTIGATION OF THE EFFECTIVE USE OF WARNING LIGHTS ON INDIANA DEPARTMENT OF TRANSPORTATION (INDOT) VEHICLES AND EQUIPMENT
}

\author{
By \\ Bob McCullouch \\ Research Scientist \\ Joint Transportation Research Program \\ School of Civil Engineering \\ Purdue University \\ and \\ Brandon Stevens \\ Highway Engineer \\ Office of Research and Development \\ Indiana Department of Transportation \\ Joint Transportation Research Program \\ Project No. C-36-67LLLL \\ File No. 9-10-89 \\ SPR-3086 \\ Prepared in cooperation with the \\ Indiana Department of Transportation and the \\ U.S. Department of Transportation \\ Federal Highway Administration
}

The contents of this report reflect the views of the authors who are responsible for the facts and the accuracy of the data presented herein. The contents do not necessarily reflect the official views or policies of the Indiana Department of Transportation or the Federal Highway Administration at the time of publication. This report does not constitute a standard, specification, or regulation.

Purdue University

West Lafayette IN 47907

December 2008 
TECHNICAL REPORT STANDARD TITLE PAGE

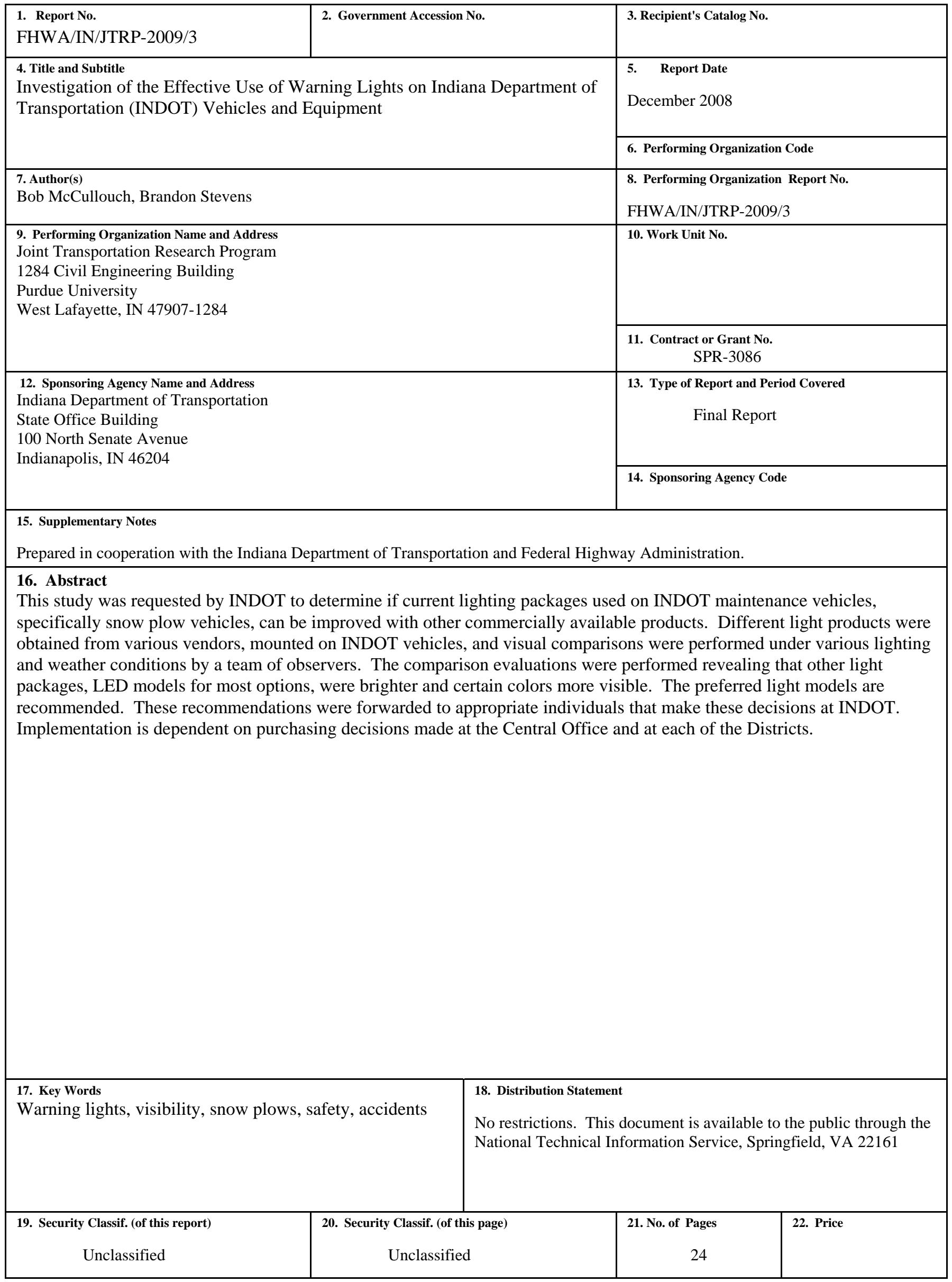

Form DOT F 1700.7 (8-69) 


\section{Introduction}

One of the Indiana Department of Transportation's greatest needs in terms of warning the motorist of work being performed along the roadway and protecting INDOT personnel is making work sites, vehicles and equipment as visible as possible. This includes providing adequate visibility during different weather conditions including snow removal operations. There are a variety of options and methods used by transportation agencies and other industries that use similar vehicles. The type, size, arrangement and color influence visibility of a vehicle. This study's objective was to evaluate and compare other lighting options to INDOT's current lighting practices to improve safety and visibility and to produce recommendations for consideration and implementation by INDOT Operations and Districts. The size and arrangement of lights was not a primary part of this study.

This study was requested by Calvin Lee, INDOT safety director at the time when the study started.

Other transportation agencies have investigated lighting issues and their work was reviewed to identify best practices. This synthesis information is summarized herein.

\section{Other Studies}

\section{$\underline{\text { NCHRP Project 6-12 - Improved Visibility for Snowplowing Operations }}$}

This research identified and evaluated in limited field tests several potential features for improving visibility. The following is a summary of these evaluations:

- During snowfall, switching off the driver-side headlamp and using an auxiliary passenger-side headlamp will reduce the back-scattered light seen by the operator.

- Shielded headlamps, louvered or cut-off type, that reduce stray light above the horizontal plane will reduce backscattered light.

- Steady-burning light bars, mounted along the rear edges of the snowplow truck, will improve other drivers' ability to detect changes in the snowplow vehicle's speed and will provide an indication of the vehicle's width. Although the features evaluated in this research yielded some 50 percent improvement in visibility for motorists following the snowplows, it should be recognized that this and other research findings were based on limited field demonstrations.

\section{Georgia DOT}

Prior to June 2005, GDOT had two 360 degree strobes mounted to the top of their arrow board and two four inch strobes on the rear bumper. In June 2005 two LED traffic advisory bars were added made up of red and clear LED's and several individual red, clear and amber strobes mounted to the rear bed rail. GDOT also used similar light 
configurations on the other trucks used in the strobe light study marking activities minus the traffic advisory bar. Since the addition of strobes and light bar they have had no accidents, before they averaged 2 to 3 per year. They credit this to the addition of the LED strobes especially the red ones. This information was provided by GDOT after a phone conversation.

\section{Strobe Light Layout / Buffer Truck \\ Before June 2005}

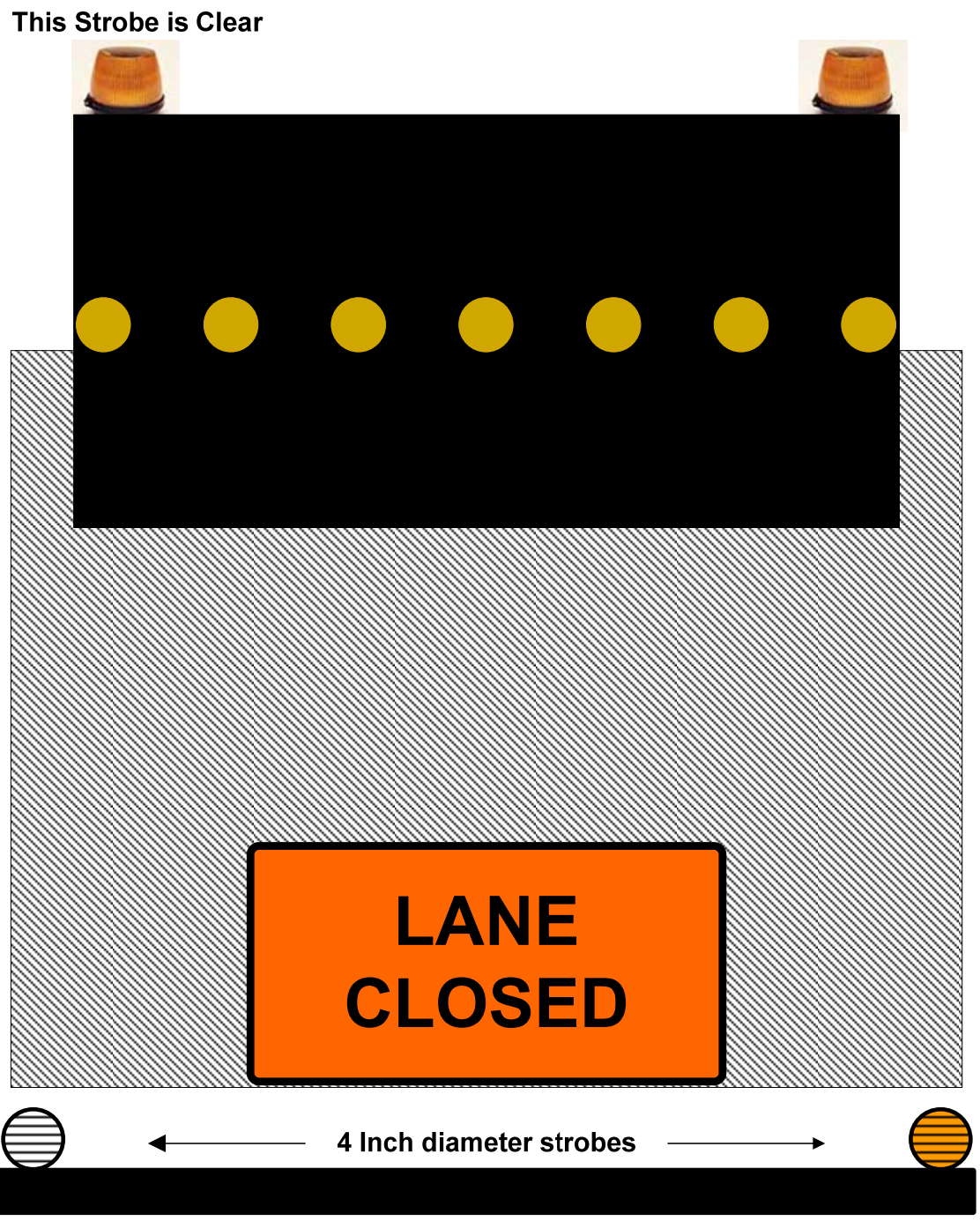

Rear Bumper

Figure 1 - Georgia DOT 


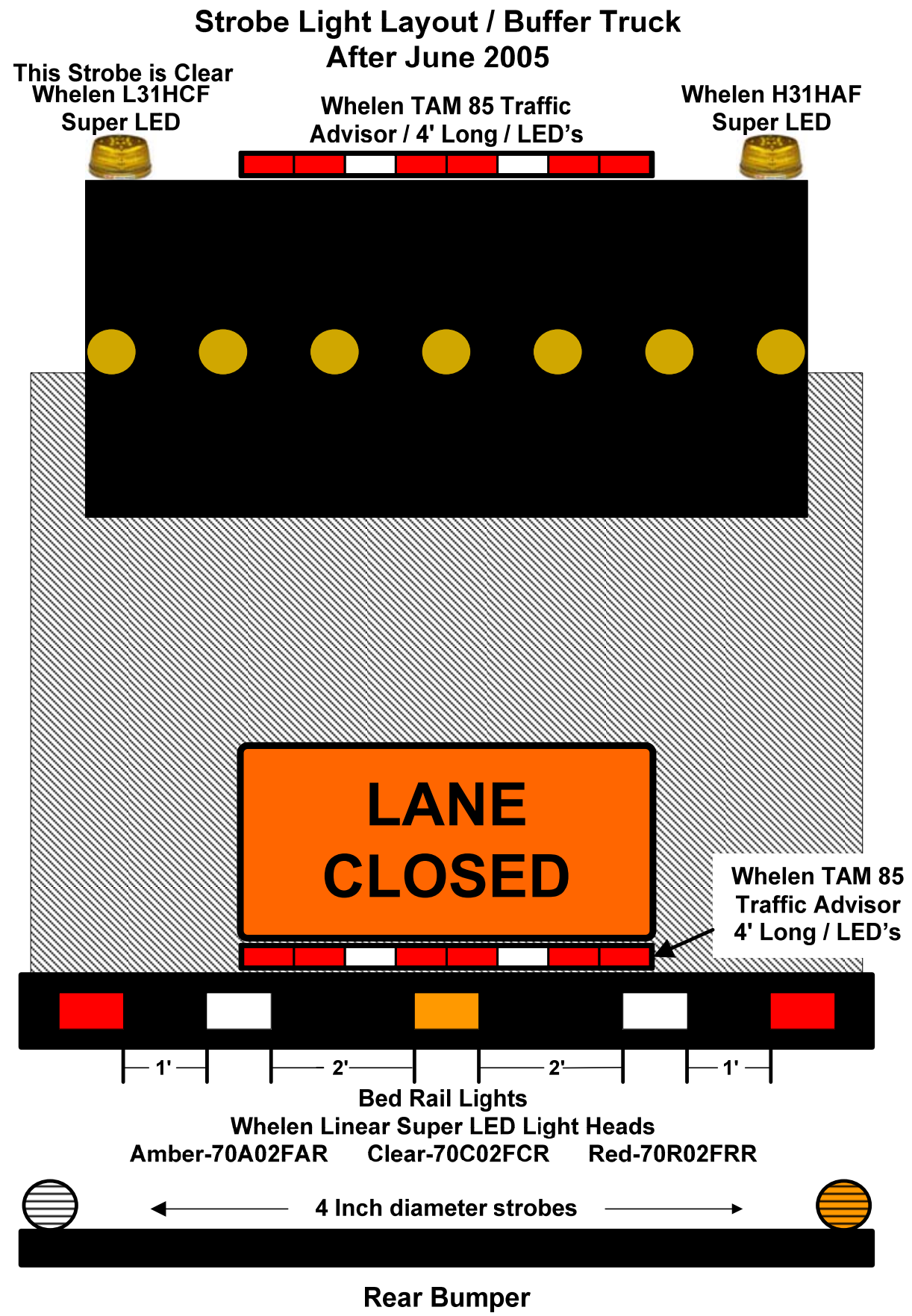

Figure 2 - Georgia DOT Rear

\section{Minnesota DOT}

The goal of this work was to understand how the processing of motion under the conditions created by blowing snow causes drivers to fail to detect that they are approaching a vehicle ahead. Light color was examined under blowing snow conditions to assess whether an equiluminant (equal brightness) situation was created. In this situation, contrast in light level is not detected, but differences in color are. When an 
equiluminant situation is created by snow, a perceptual illusion lowers the ability to perceive approach. The results indicate that colors in the red-yellow part of the spectrum can create a dangerous equiluminant situation in blowing snow and fog. They were unable to find an optimum color to paint snowplows to make them less susceptible to rear-end collisions.

Perception studies investigated the ability of the visual system to detect the expansion pattern that drivers use to perceive that they are approaching a vehicle. They found that low contrast created by a snow cloud greatly reduces the ability to perceive approach. Flashing lights that increase conspicuity, substantially increased the chances of a crash. Additional ways to improve the placement of warning lights based on these findings were proposed.

This information was obtained from phone conversation.

\section{South Dakota DOT}

South Dakota did a study on this topic and produced the following recommendations for their plow trucks:

1. Additional plow head lights, turn signals and clear 100 watt fog lights (8-10" convex mirror mounted on the passenger side).

2. 2 (Whelen \#S360SAP) Amber color strobe lights mounted on the corners of rock rack elevated 9" to prevent flashback in the mirrors.

3. One 4" white spot light mounted bottom of the cab to light mid-mount wing.

4. Amber color (Whelen \#70A00FAR) LED light mounted top back of wing.

5. 2 Elevated amber color (Whelen \#70A00FAR) LED lights mounted at least 11' above the ground.

6. 2 Elevated red stop/turn (Whelen \#70R00XRR) LED lights mounted just below the elevated amber lights.

7. 2 White (Whelen \#70C00FCR) LED lights mounted outside top corner of truck box.

8. One 4" white spot light mounted above sander chute on drivers side to light discharge of material at night.

This information was obtained as a result of a phone conversation. 


\section{$\underline{\text { Kansas DOT }}$}

Kansas DOT has used the Whelen DOT 3 System 102A strobe system on their dump trucks for years, but have began purchasing the following for approximately half of their trucks. It is an LED system from Whelen and is more visible compared to the other Whelen systems. It is a Whelen KDOT L16 DOT-LED System consisting of one [1] 96" Edge Bar Mounted in the center of the cab roof area consisting of two [2] Freedom Linear 12 Amber LEDS on each corner and two [2] Freedom 400 Series Linear 12 directional amber LED's on the front and rear middle of lightbar.

This information was obtained as a result of a phone conversation with KDOT.

\section{$\underline{\text { Wisconsin DOT }}$}

The Wisconsin DOT contracts with 72 local county highway departments in Wisconsin to maintain the state highway system. The county highway departments are responsible for the purchase and maintenance of any equipment necessary to perform this highway maintenance service. WisDOT provides a winter maintenance truck lighting guideline in their Maintenance Manual. The extra lighting they recommend for snow plow trucks includes:

1) High intensity discharge (H.I.D.) lamps as auxiliary lighting to the truck headlights

2) A LED light on the end of the wing plows to make them more visible.

This information was obtained as a result of a phone conversation with WisDOT.

\section{Nevada DOT}

The below images show the lighting system used by Nevada DOT. These images show the lighting configuration on the front and back but no description of the type of lights used. 


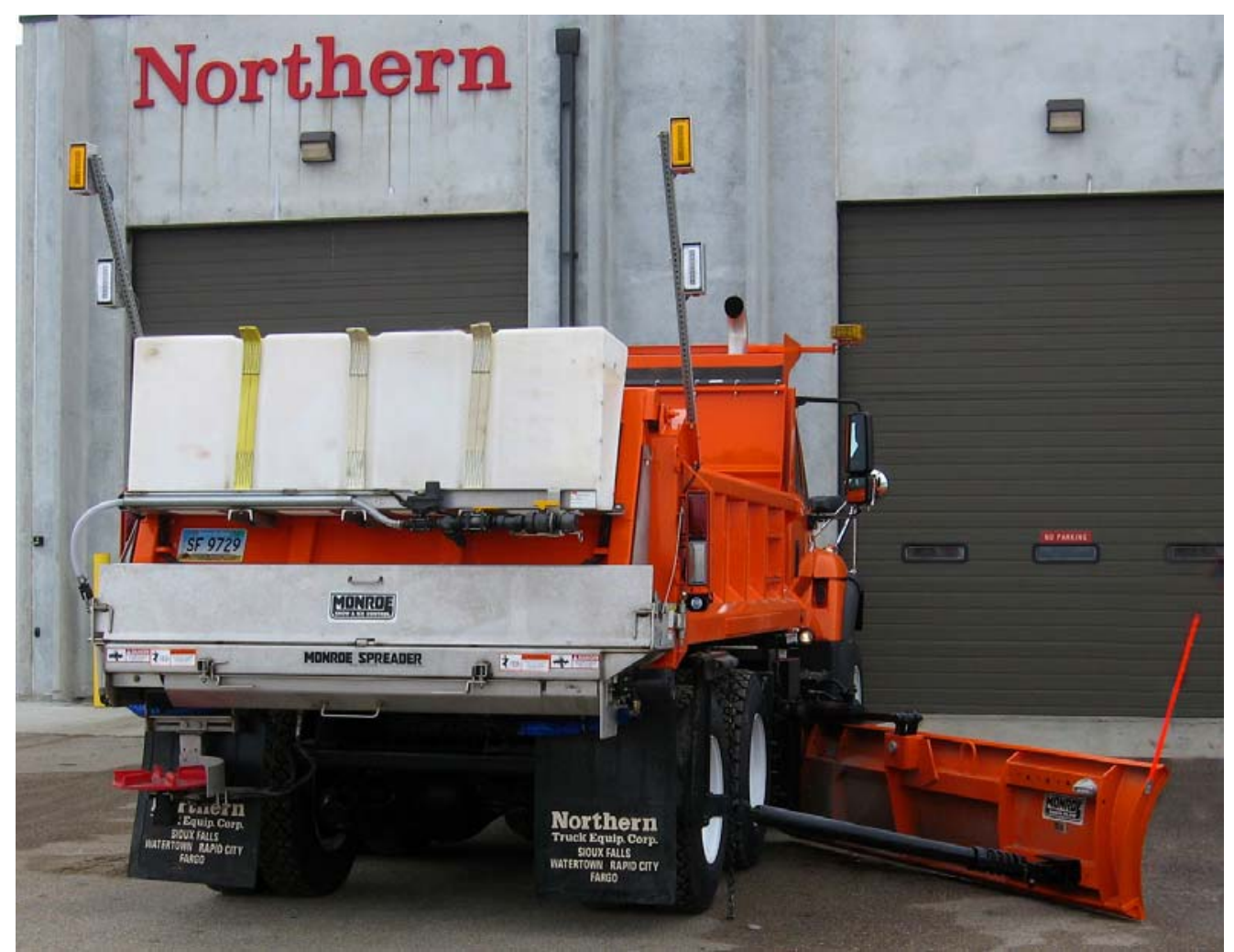

Figure 3 - Nevada Rear

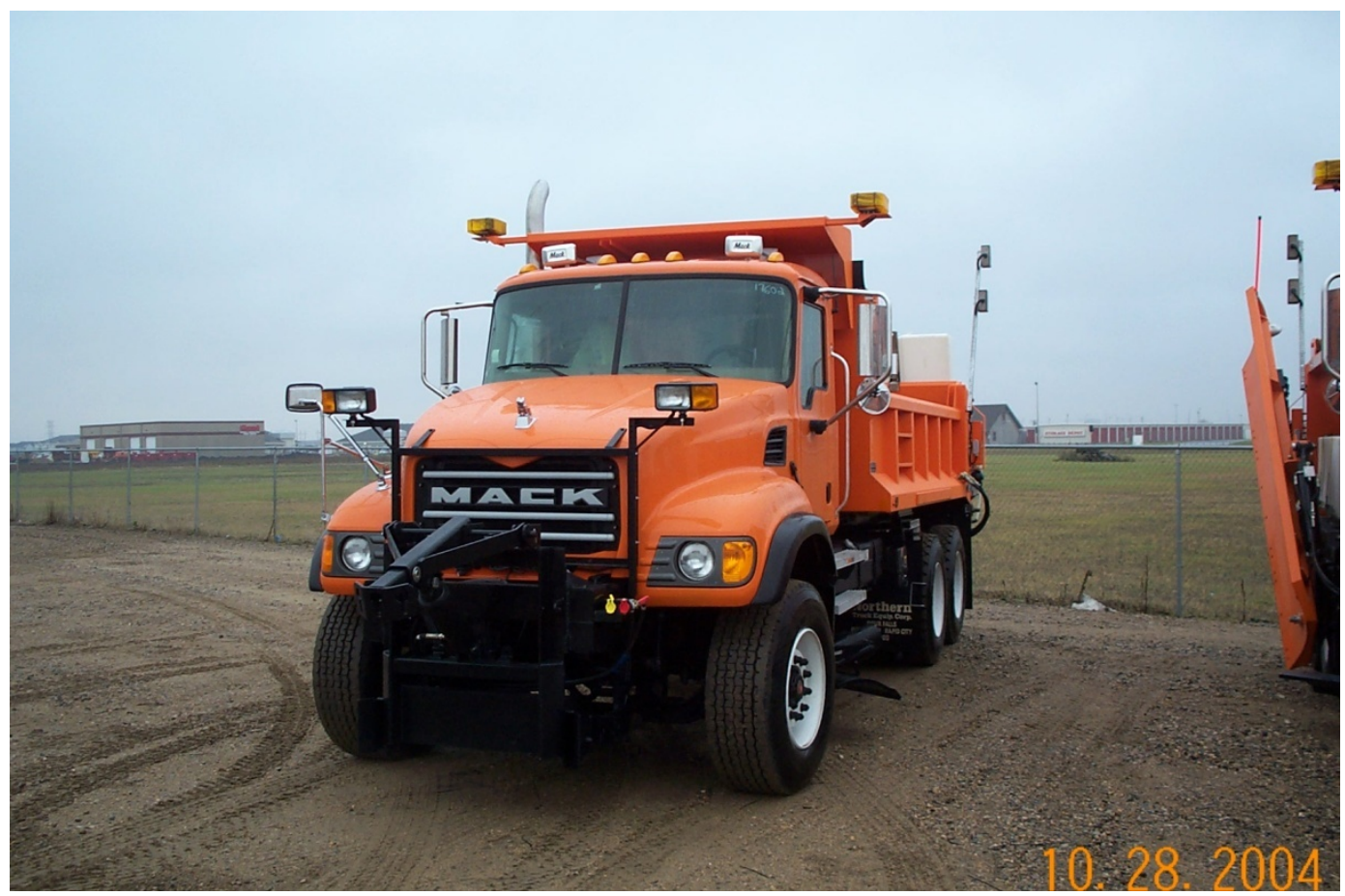

Figure 4 - Nevada Front

This information was obtained as a result of a phone conversation. 
Alaska

Alaska uses combinations of blue and yellow strobes mounted front and rear on their heavy equipment. This provides great visibility even in light and blowing snow conditions.

This information was obtained through a phone conversation with an Alaskan DOT employee.

\section{Caltrans}

The California Department of Transportation (Caltrans) currently has a current research project on warning lights. The project is being developed as a Caltrans sponsored University of California, Berkeley research project. The project consists of two parts and is estimated to run for three years. The plan is to develop and test improved emergency warning lights for work zone vehicles (year 1), and enhanced rear warning lights for shadow trucks (years $2 \& 3$ ), both intended to improve visibility and improve reaction times for drivers approaching the work zone. The research group aims to design, fabricate and test an emergency warning light package that will uniquely identify Caltrans maintenance vehicles and which will thus convey to the public the special hazardous nature of the portion of the highway where they are seen. The improved emergency warning lights will employ ITS principles and should be able, if deployed, to lead to meaningful reductions in work zone collisions. This study will examine the visual properties (speed of human response) of our proposed improvement. A prototype will be delivered for possible field operational testing at project's end.

This information was obtained from CALTRANS as a result of a phone conversation

\section{Work Plan}

This research project investigated various lighting options available to provide the most desirable level of visibility for vehicles and equipment. INDOT vehicle lighting vendors were contacted ask asked to participate in the study. Each vendor described their product lines for this application and demonstrated some of their products. Light emitting diode (LED) lights are the latest technology. They produce brighter and better quality light but they are significantly more expensive. The vendors committed to donating some of their products, some of the more expensive items (light bars) were purchased. The vendors that presented were:

Federal Signal

PSE

Whelen

Soundoff Signal

CRS 
The lighting equipment obtained from the vendors were field evaluated by personnel associated with INDOT safety, Research, equipment and the district(s) to determine their effectiveness from a visibility perspective. Lighting recommendations are made for implementation. More specifically the activities are:

1. Accumulate information on similar studies. Evaluate the findings and talk with personnel involved in these studies.

2. Contact light vendors and provide information on the study and ask for participation.

2. Purchase and install lighting systems on two trucks to be used for field evaluations. The field evaluations were performed under four different weather and lighting conditions by an observation team averaging 6 individuals. The observations were individual comparisons between similar lighting options. The results of these observations are reported.

Perform field tests and subjective evaluations of the lighting system in various weather conditions. Due to safety concerns all field evaluations were off road at the Research Division facility. The evaluations or observations were from the approaching vehicle (front and back) perspectives. Field observations were done in four different weather and lighting conditions: snow, cloudy, bright sun, and night.

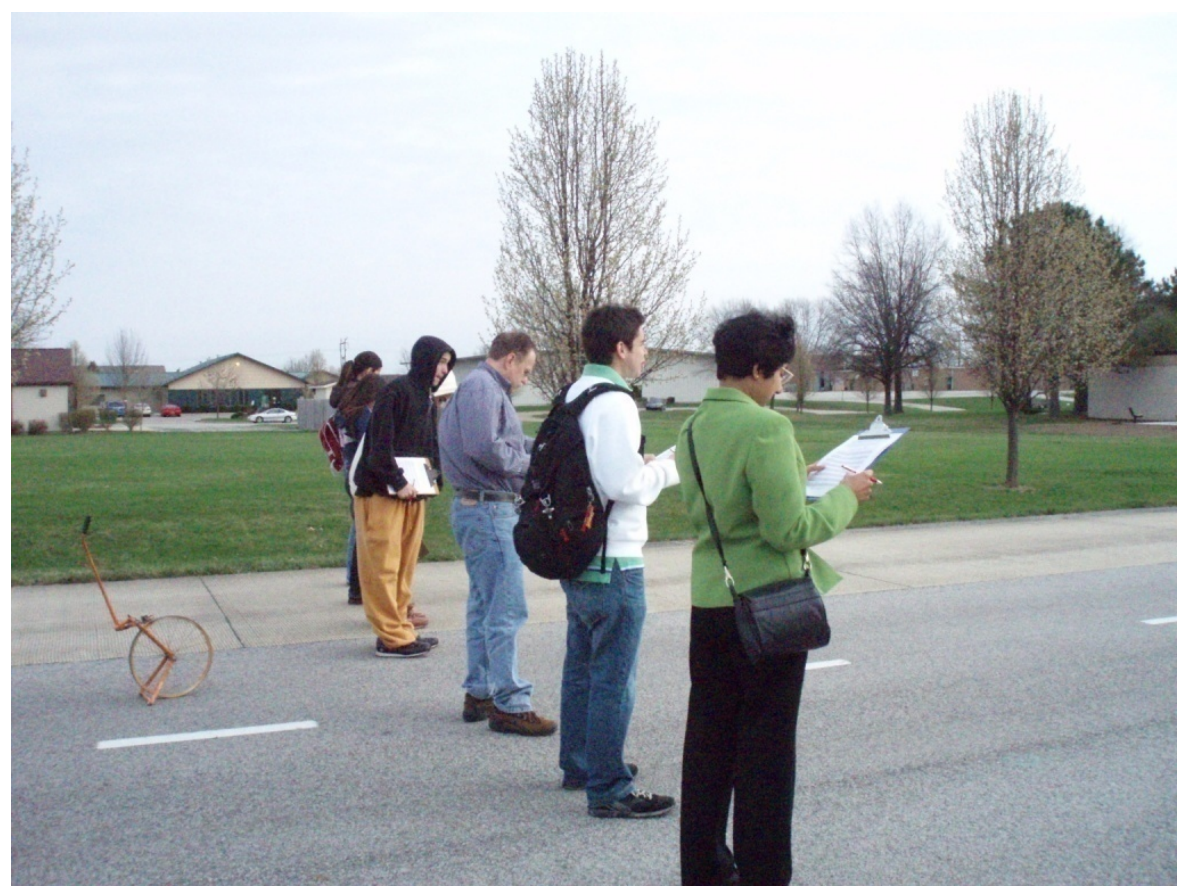

Figure 5 - Field Observations 


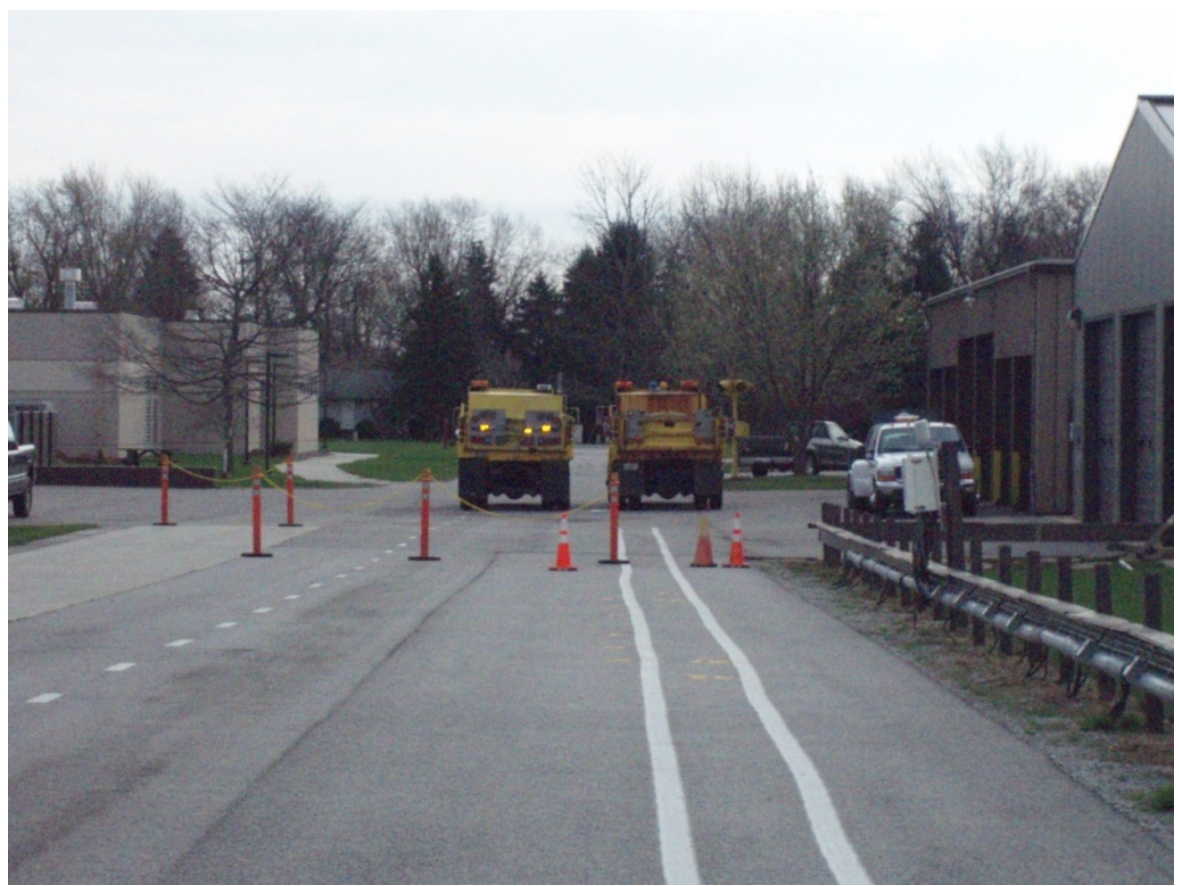

Figure 6 - Cloudy Observation

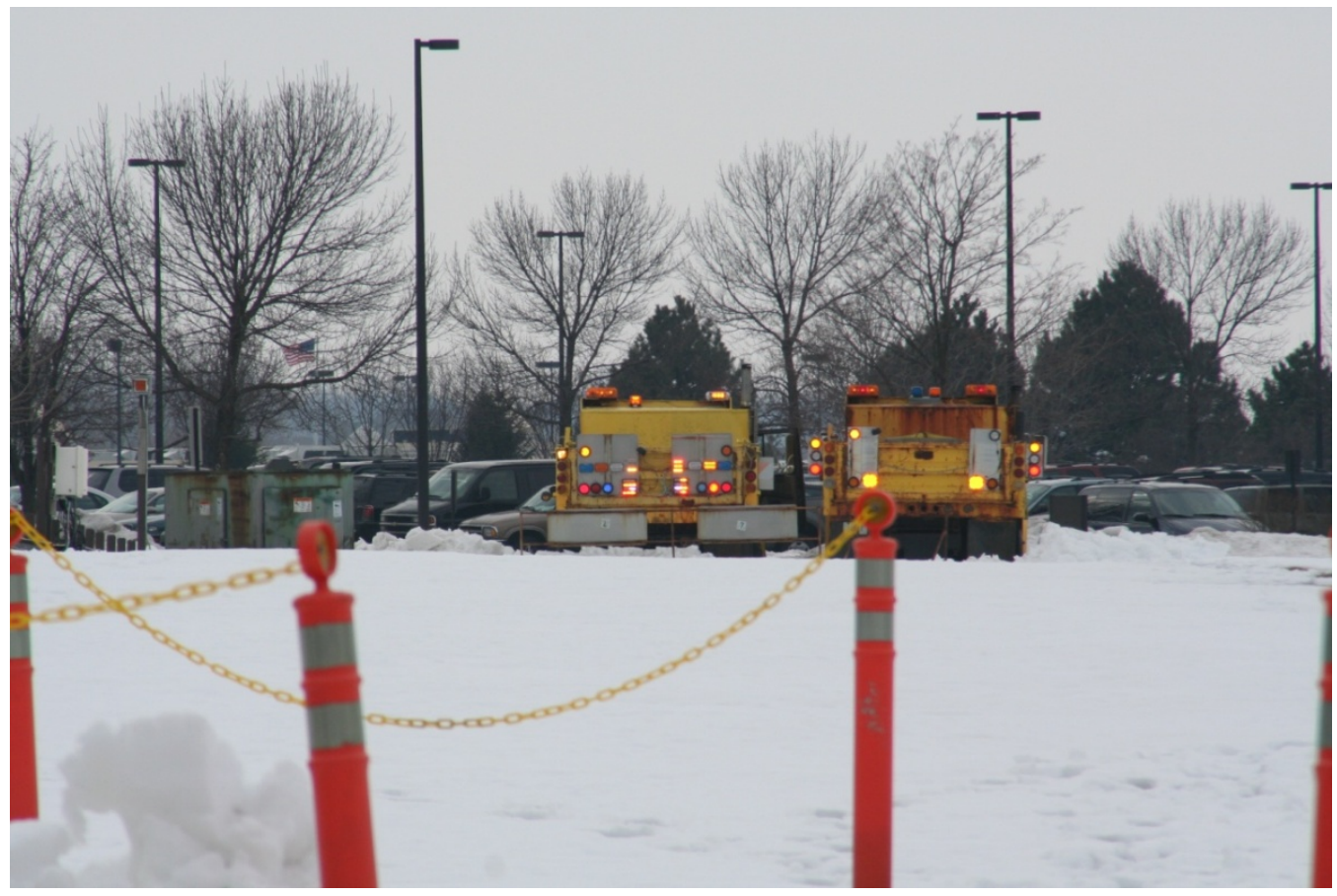

Figure 7 - Snow Observation 
The evaluations were recorded manually using paper forms. A partial form is shown below.

Table 1 - Field Observation form

Date $3 / 29 / 07$

\begin{tabular}{|c|c|c|c|c|c|c|c|}
\hline Date 3/29/07 & LIGHT \# & Weather Conditic & 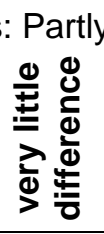 & Su & & & 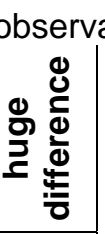 \\
\hline No difference & 0 & 1 & 1 & 2 & 3 & 4 & 5 \\
\hline No difference & 2 & 1 & 1 & 2 & 3 & 4 & 5 \\
\hline No difference & 2 & 3 & 1 & 2 & 3 & 4 & 5 \\
\hline No difference & 2 & 10 & 1 & 2 & 3 & 4 & 5 \\
\hline No difference & 2 & 11 & 1 & 2 & 3 & 4 & 5 \\
\hline No difference & 2,15 combo & 4 & 1 & 2 & 3 & 4 & 5 \\
\hline No difference & 11(RED) & 14(BLUE) & 1 & 2 & 3 & 4 & 5 \\
\hline No difference & 12(AMBER) & 14(BLUE) & 1 & 2 & 3 & 4 & 5 \\
\hline No difference & 8 & 12 & 1 & 2 & 3 & 4 & 5 \\
\hline No difference & 8 & 9 & 1 & 2 & 3 & 4 & 5 \\
\hline No difference & 8 & 15 & 1 & 2 & 3 & 4 & 5 \\
\hline No difference & 9 & 15 & 1 & 2 & 3 & 4 & 5 \\
\hline
\end{tabular}

The observer indicates with light is brighter and to what degree and if no difference then indicate accordingly.

The vendors that participated and their light models were the following. These light products are sold to agencies and companies for the sole purpose of safety warning. They are used on various types of maintenance, construction, and emergency vehicles.

\author{
Federal Signal \\ 252653-03 blue strobe \\ 252651-02 amber strobe, class 1 \\ $607123 \mathrm{red}$ \\ 607123 blue \\ 607123 amber \\ QL64XFC-R quadflare red \\ QL64XFC-B quadflare blue \\ QL64XFC-A quadflare amber \\ 454202-25 amber highlighter \\ 454202-35 blue highlighter
}




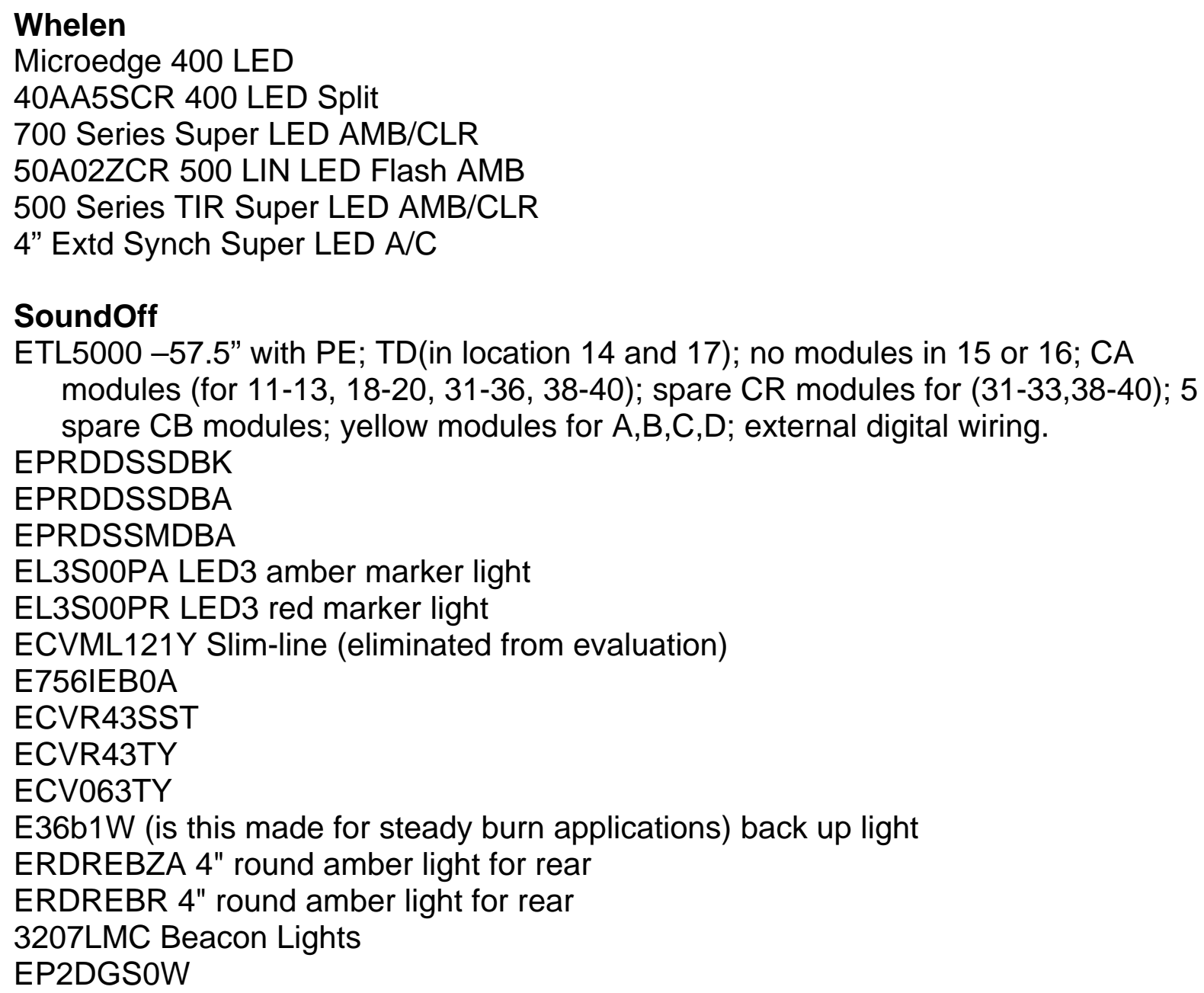



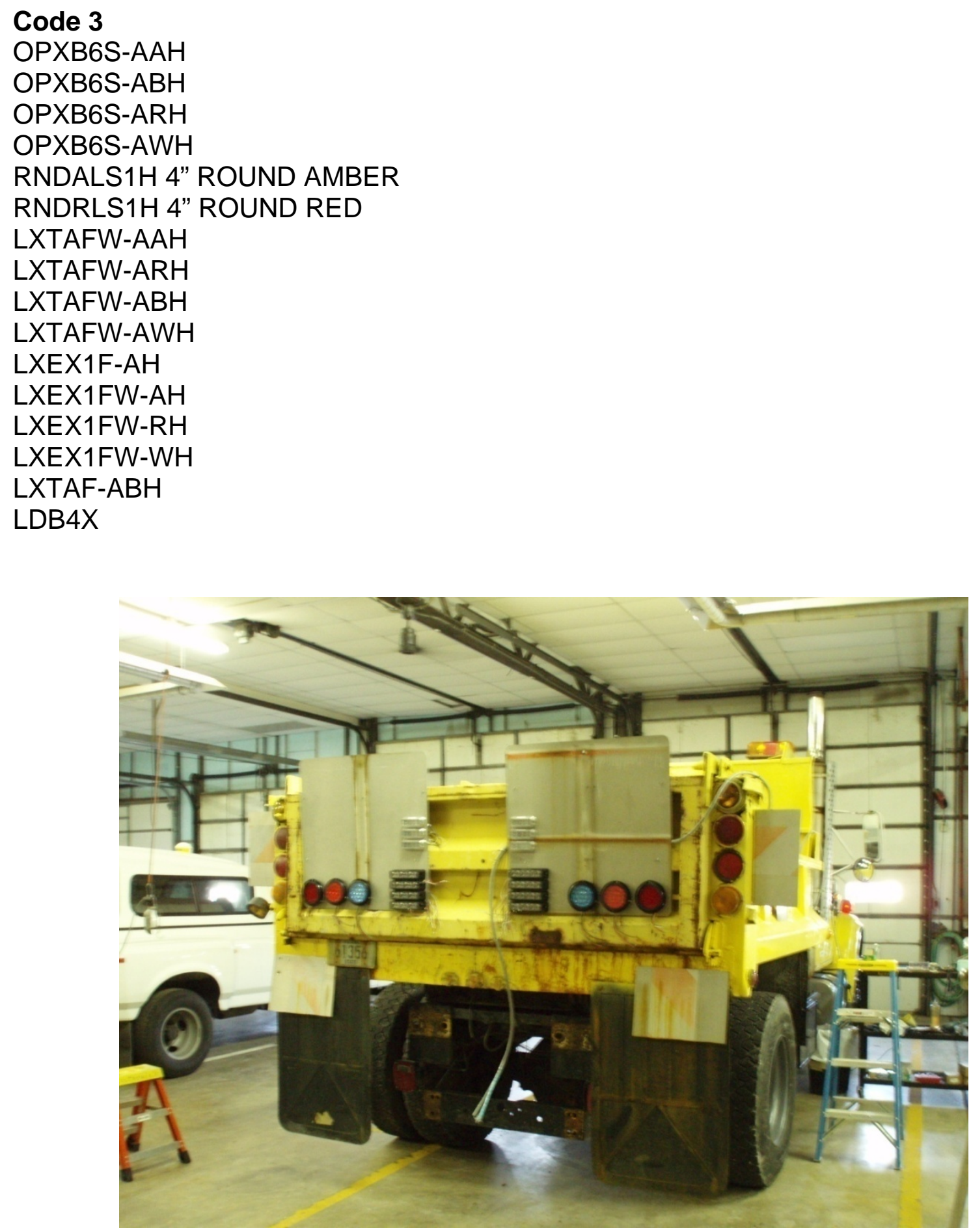

Figure 8 INDOT test truck being equipped with study lights 


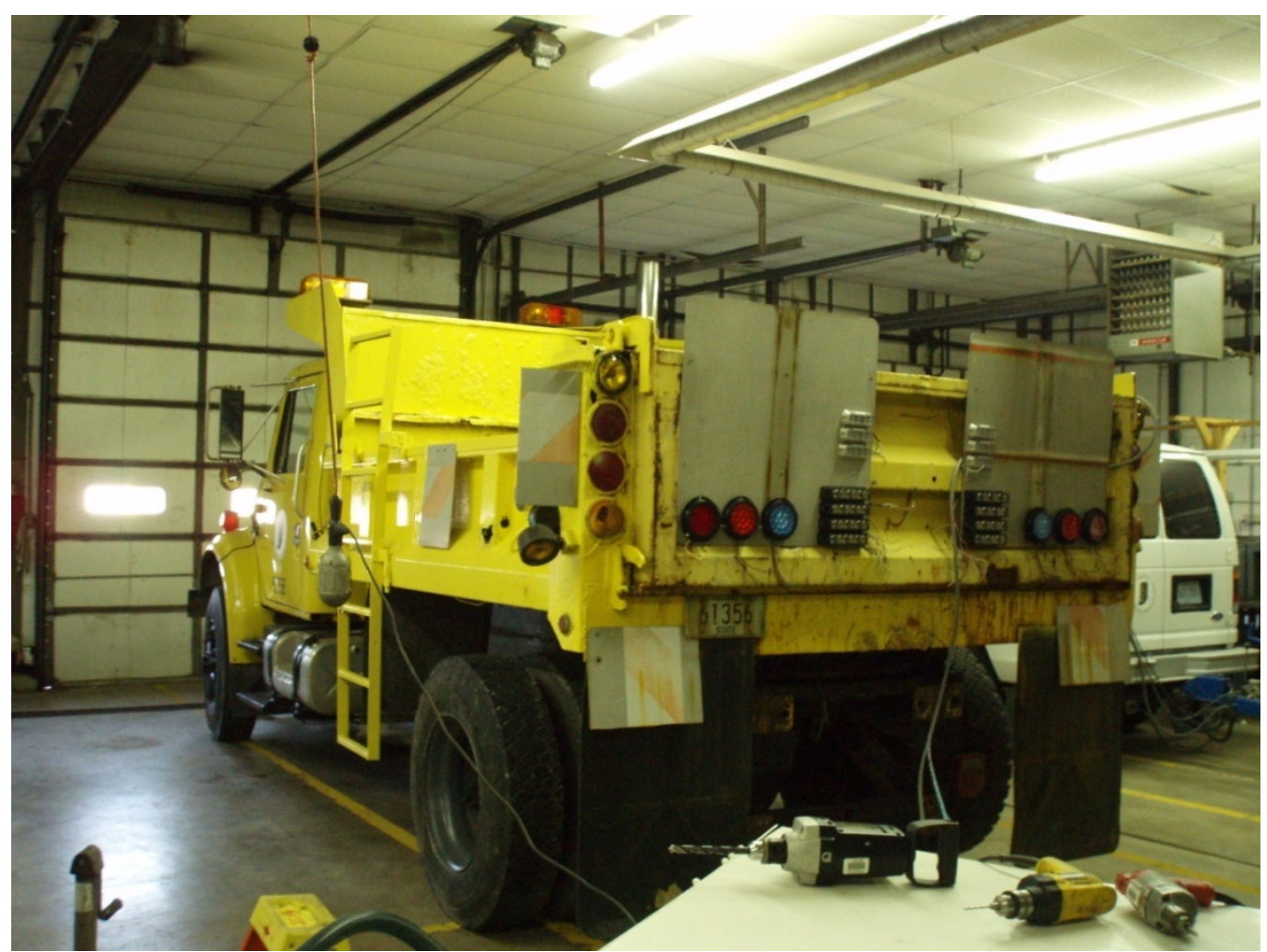

Figure 9 - INDOT Test Truck being equipped with test lights

\section{Current Light Configurations}

Figures 10 and 11 show the current light configurations on an INDOT maintenance truck. Districts have some latitude with lighting configurations so this could vary by District. Looking at these two images the main lighting components for the front are a light bar on top with two pairs of flood lamps. The back side has a column of round tail lights on each side, starting with amber on top, two reds, and a white backup light.

One of the study questions is: Are there brighter, more visible lights that can be used to increase the safety and visibility of INDOT equipment? To answer that question two INDOT salvaged vehicles were setup with the lighting products previously listed, and field observations made under differing weather and light conditions. The observations consisted of direct comparisons between similar light products in the categories: round and oval, LED surface, light bars, beacons, and white lights. The comparison asked the observer to select which option was brighter and more visible. 


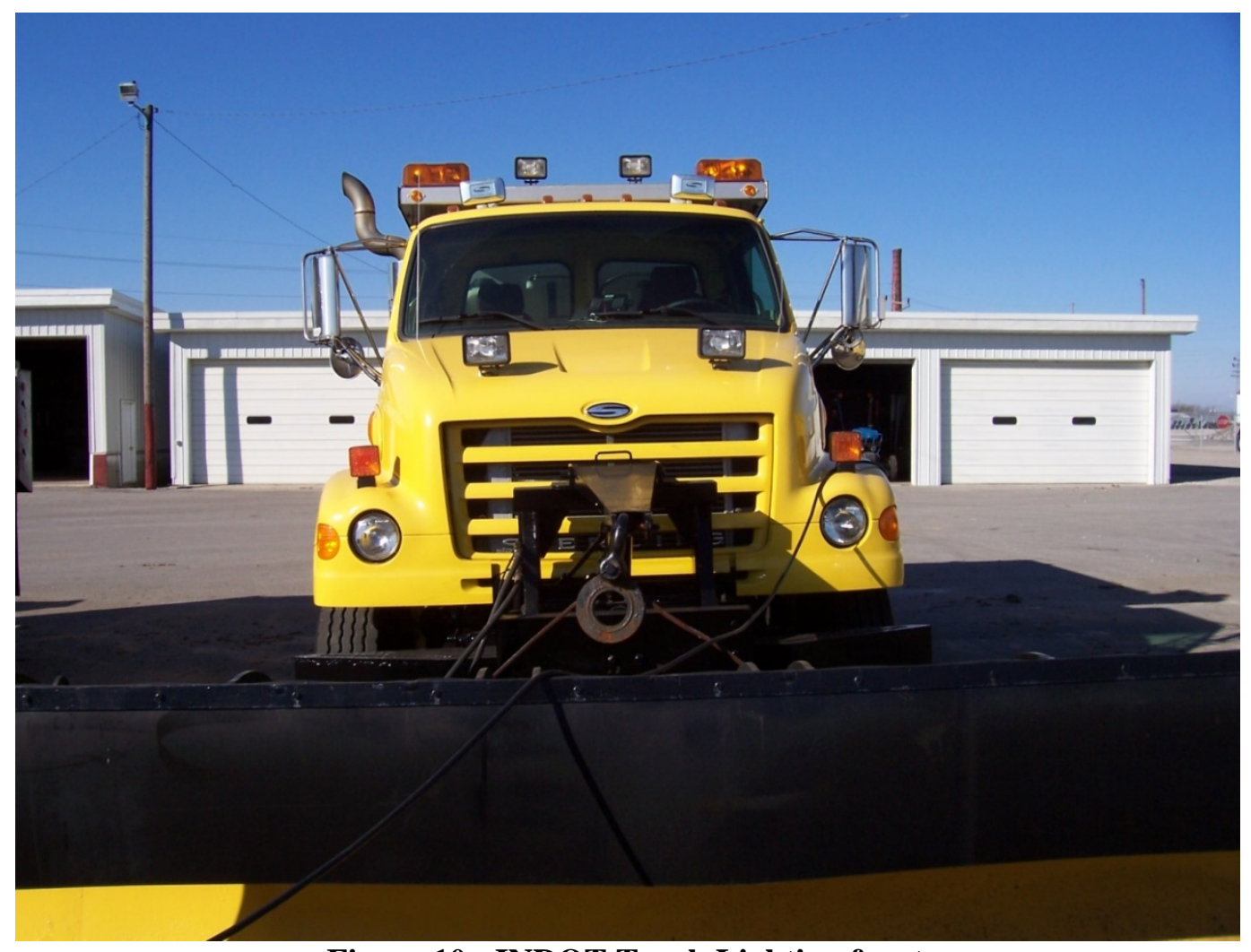

Figure 10 - INDOT Truck Lighting front

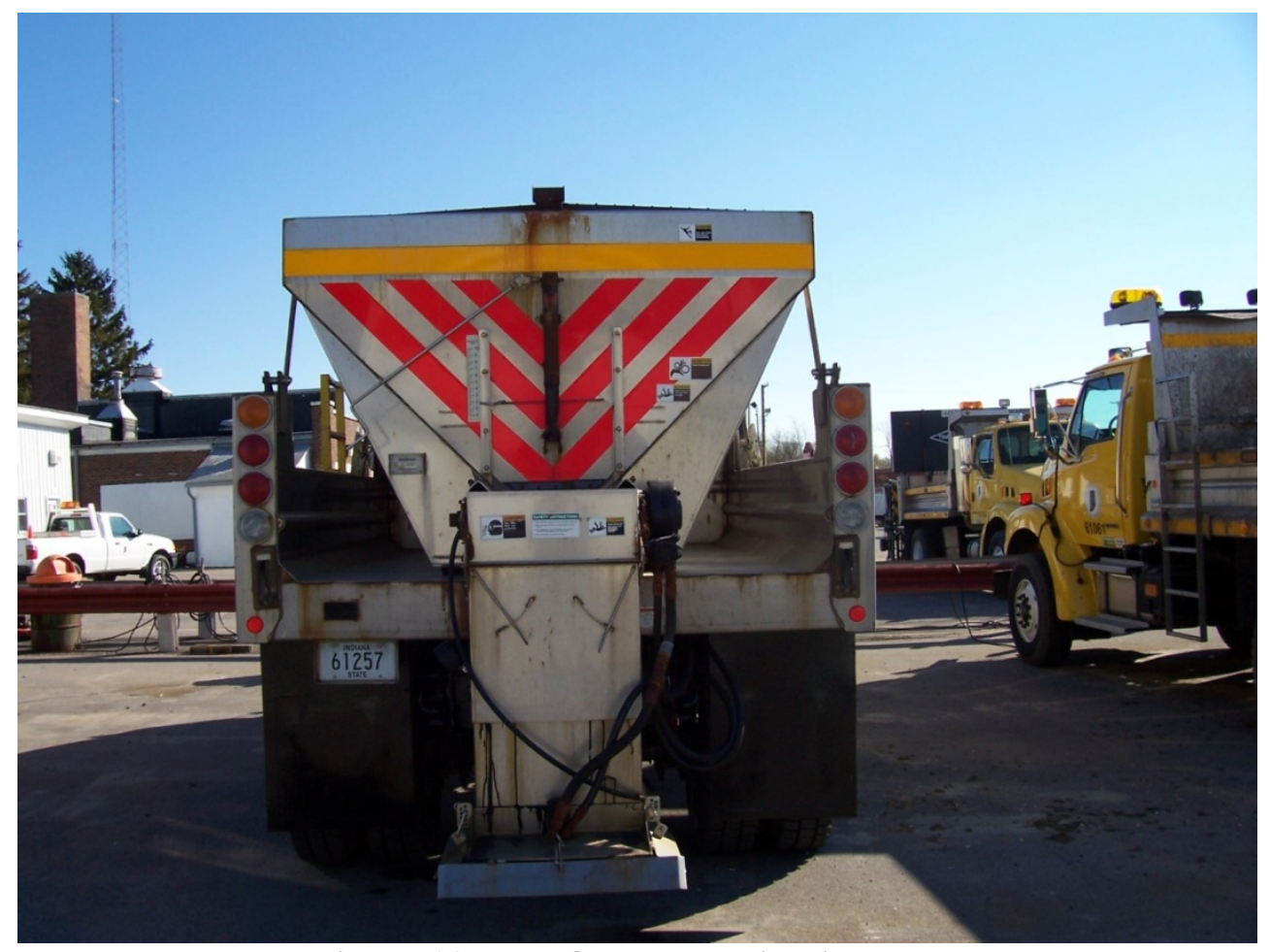

Figure 11 - INDOT Truck Lighting Rear 


\section{Light Categories}

There were five different light categories evaluated:

1. Round and oval

2. LED surface

3. Light Bars

4. Beacons

5. White lights

The field observations consisted of a direct comparison between the light options in each category. For each category, the light options are shown and the comparison results given.

\section{Round and oval}

\begin{tabular}{|l|l|l|l|l|}
\hline Part No. & Color & Description & Manf. & Notes \\
\hline 1157 light bulb & Red & Brake Light & INDOT & \\
\hline RNDRLS1H & Red & 4" Round & Code3 & \\
\hline 607123 & Red & 4" round - LED & Fed Sig & rubber grommet deterioration \\
\hline 607123 & Blue & 4" round - LED & Fed Sig & rubber grommet deterioration \\
\hline 607123 & Amber & 4" round - LED & Fed Sig & $\begin{array}{l}\text { Partial burnout / malfunction on light } \\
\text { sequence. Preferred. }\end{array}$ \\
\hline Erdrebzr & Red & 4" Round & Soundoff & GEN2 LED \\
\hline ECVR43sst & Red & 4" Round & Soundoff & GEN2 LED \\
\hline Erdrebza & Amber & 4" Round & Soundoff & GEN2 LED \\
\hline RNDALS1H & Amber & 4" Round & Code3 & \\
\hline E756IEB0A & Amber & 7" LED round light & Soundoff & internal moisture, Preferred \\
\hline $10-103-20$ & Red & 4" Stop/Turn tail light & CRS & \\
\hline $10-103-30$ & Amber & 4" Turn Signal & CRS & \\
\hline Ecvr43ty & Amber & 4" yellow & Soundoff & GEN2 LED \\
\hline 1157 incandescent bulb & amber & 4" round & Soundoff & \\
\hline G2F8500R & Red & 7" round LED warning & CRS & moisture inside light \\
\hline 1157 incandescent bulb & Red & Truck Brake light & INDOT & \\
\hline Par36 & Amber & Truck rear hazard light & INDOT & \\
\hline 2EA00ZCR & Amber & 4" round super LED & Whelen & \\
\hline
\end{tabular}

In the direct comparison with the current INDOT lights and the others shown in the above table, two lights were rated more visible and brighter than the others. They were:

Federal Signal, part \# 607123, amber 4" round LED and Soundoff , part \# E756IEBOA, amber 7" round LED 
There was not a direct comparison between the two due to the size difference, 4" and 7". The Soundoff product had internal moisture problems.

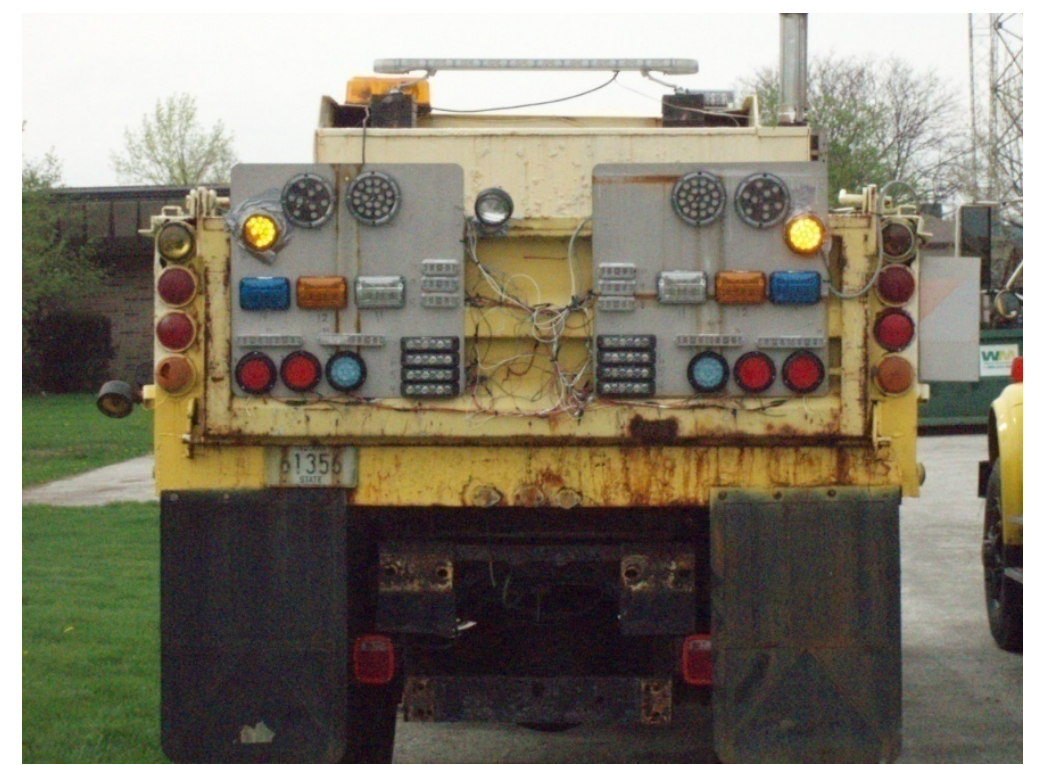

Figure 5 - Federated Signal 4" Round Amber

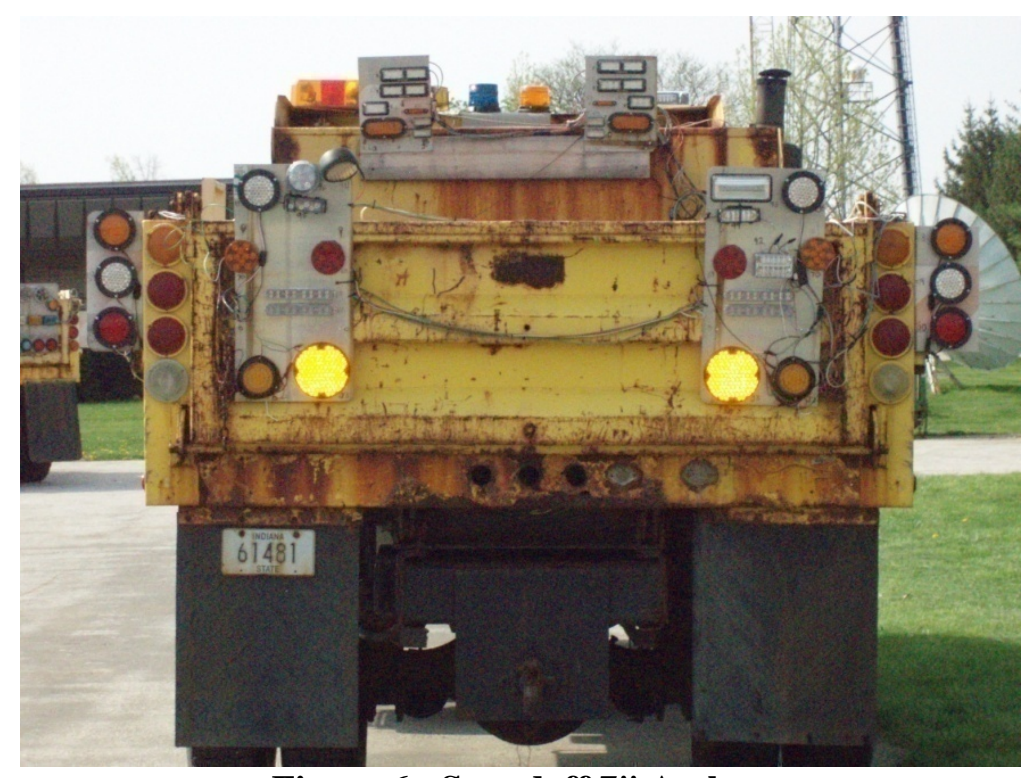

Figure 6 - Soundoff 7" Amber 


\section{LED Surface Lights}

\begin{tabular}{|c|c|c|c|c|}
\hline OPXB6S-ARH & Amber/Red & LED 5" x 2" & Code3 & \\
\hline OPXB6S-AWH & Amber/White & LED 5" x 2" & Code3 & \\
\hline OPXB6S-AAH & Amber/Amber & LED 5" x 2" & Code3 & \\
\hline OPXB6S-ABH & Amber/Blue & Led 5" x 2" & Code3 & \\
\hline LXEX1F-AH & Amber & LED 3" x 2" & Code3 & Preferred \\
\hline LXEX1FW-AH & Amber & LED 3" x 2" Wide Angle & Code3 & \\
\hline LXEX1FW-RH & Red & LED 3" x 2" Wide Angle & Code3 & \\
\hline QI64xfC-r & Red & LED - 4" x 6" quadflare flasher & Fed Sig & \\
\hline Q164xfc-a & Amber & LED - 4" x 6" quadflare-flasher & Fed Sig & Partial burnout, Preferred \\
\hline LXEX1FW-WH & White & LED exterior - 5" $\times 2$ " & Code3 & Possible plow lights \\
\hline Predator II extreme angle & White & LED - 5" x 2" & Soundoff & \\
\hline Ql64xfc-b & Blue & LED quadflare - 4" × 6" -flasher & Fed Sig & \\
\hline G2F8500A & Amber & 7" LED warning light & CRS & \\
\hline LXTAFW-AWH & Amber/White & LED - 9" x 2" & Code3 & \\
\hline LXTAFW-AAH & Amber/Amber & LED - 9" x 2" & Code3 & moisture inside light \\
\hline El3s00pr & Red & LED3 marker 3" x 1" & Soundoff & moisture inside light. Preferred \\
\hline El3s00pa & Amber & LED3 marker 3" x 1" & Soundoff & \\
\hline Ecv063ty & Amber & 6" oval -LED & Soundoff & GEN2 LED \\
\hline Ecvml121y & Amber & LED 5" $\times 2 "$ & Soundoff & not evaluated due to intensity \\
\hline Eprdssmdba & Amber & LED - 5" x 2.4" & Soundoff & internal moisture \\
\hline Eprddsdbk & Amber/Amber & LED - 5" x $2.4 "$ & Soundoff & internal moisture \\
\hline Eprddsdba & Amber/Red & LED - 5" x 2.4" & Soundoff & internal moisture \\
\hline LXTAFW-ARH & Amber/Red & LED - small rectangle & Code3 & \\
\hline LXTAF-ABH & Amber/Blue & LED - small rectangle & Code3 & \\
\hline 40AA55CR - 400 series & Amber & LED - 5" x 3" & Whelen & \\
\hline 70A02FCR & Amber & Super LED & Whelen & \\
\hline $01-0664633110$ & Amber & 500 Series Linear LED & Whelen & \\
\hline $02-0363763314$ & Amber & 500 Series Linear LED & Whelen & \\
\hline
\end{tabular}

For these lights, 45 different comparisons were made. Observers rated all the LED lights high in terms of brightness and visibility. Most observers preferred the amber color. Preferred lights were:

Code 3 - LXEX1F -AH Amber Soundoff - EL3SOOPR Red Soundoff - EL3SOOPR Amber

Federal Signal - QL64XFC-Amber 


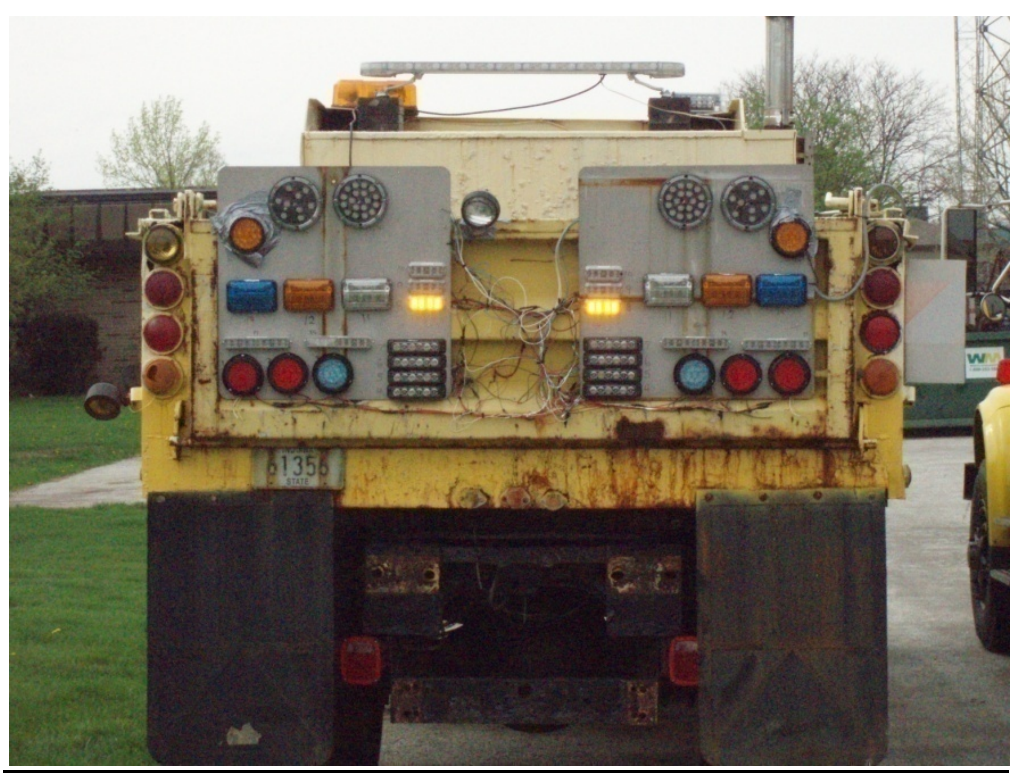

Figure 7 - Code 3 - LXEX1F -AH Amber

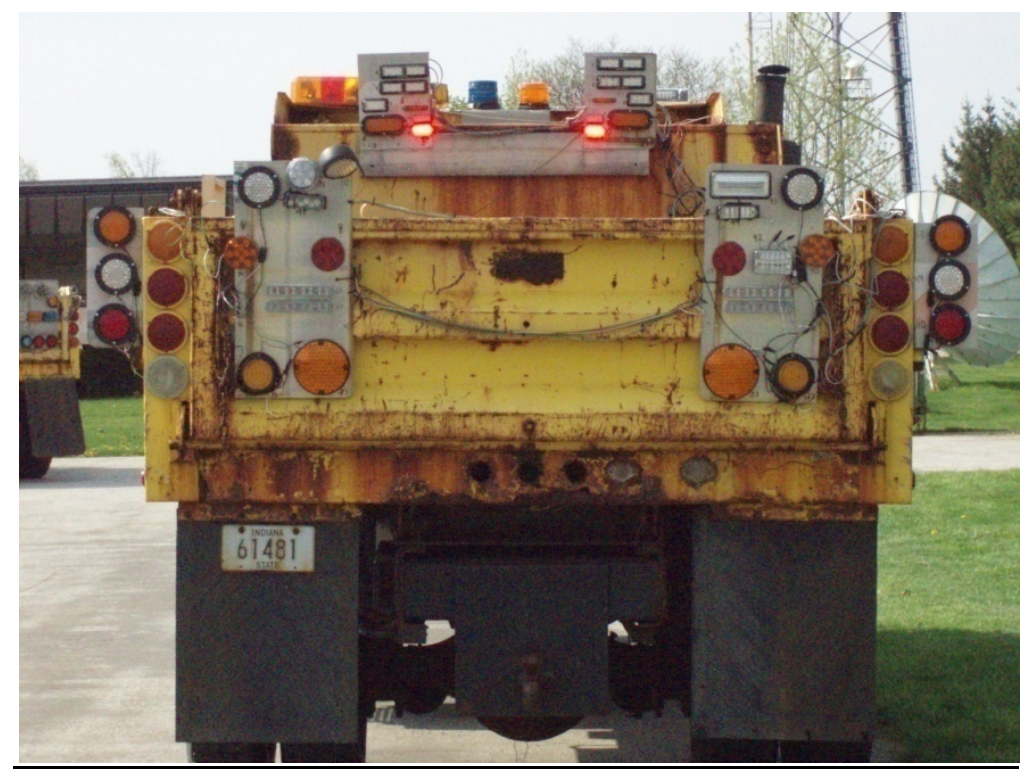

Figure 8 - Soundoff - EL3S00PR Red 


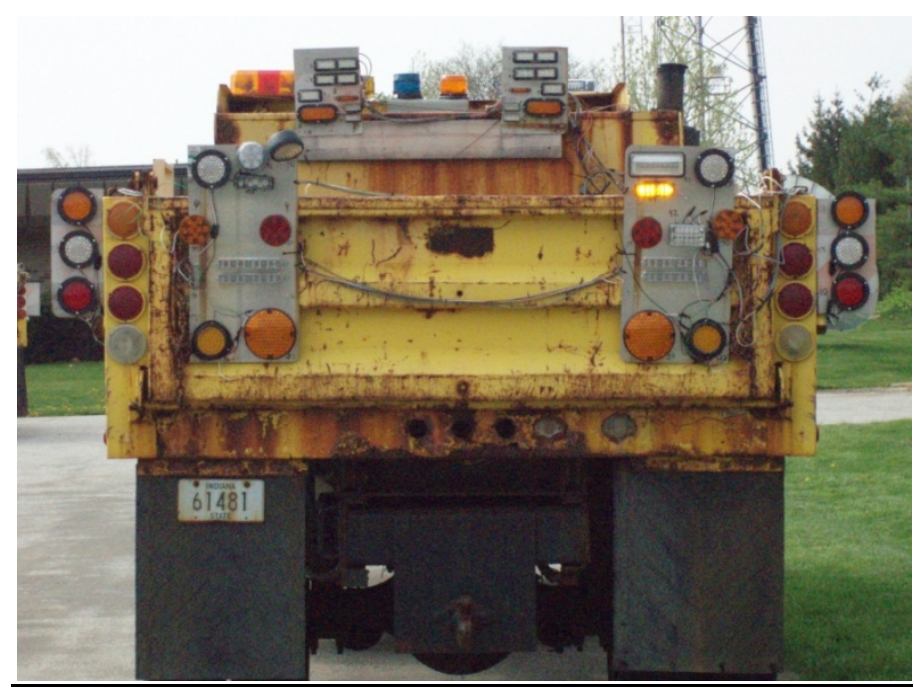

Figure 9 - Whelen 01-0664633110 Amber

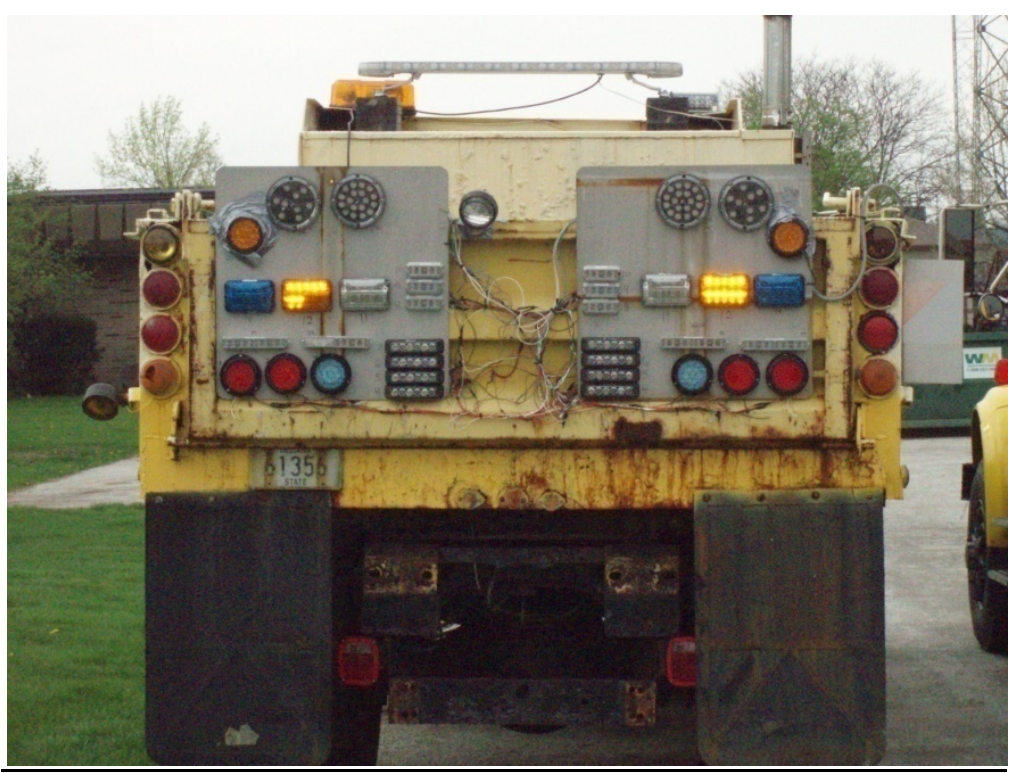

Figure 10- Federal Signal QL64XFC-A 


\section{Light Bars}

\begin{tabular}{|c|l|l|l|l|l|}
\hline $21 \mathrm{~L}$ & Duo Beam LDB4X & amber & LED Beam light for top of truck & Code3 & \\
\hline 26 & $454202-25$ & amber & minilight bar & Fed Sig & Magnetic mount \\
\hline 27 & $454202-35$ & blue & minilight bar & Fed Sig & Magnetic mount \\
\hline 71 & Highlighter & Amber & Mini light bar & Fed Sig & Current rotating light \\
\hline 71 & & & Clear Light Bar & Whelen & \\
\hline 36 & ETL5000 & amber (Amber/Red)rear & light bar & Soundoff & Preferred \\
\hline 1 & & Amber & Yellow Cube on truck top & Whelen & \\
\hline
\end{tabular}

Nineteen different comparison combinations were made among the light bar products. One light bar was preferred by the observers over the others and that was: Soundoff model ETL5000.

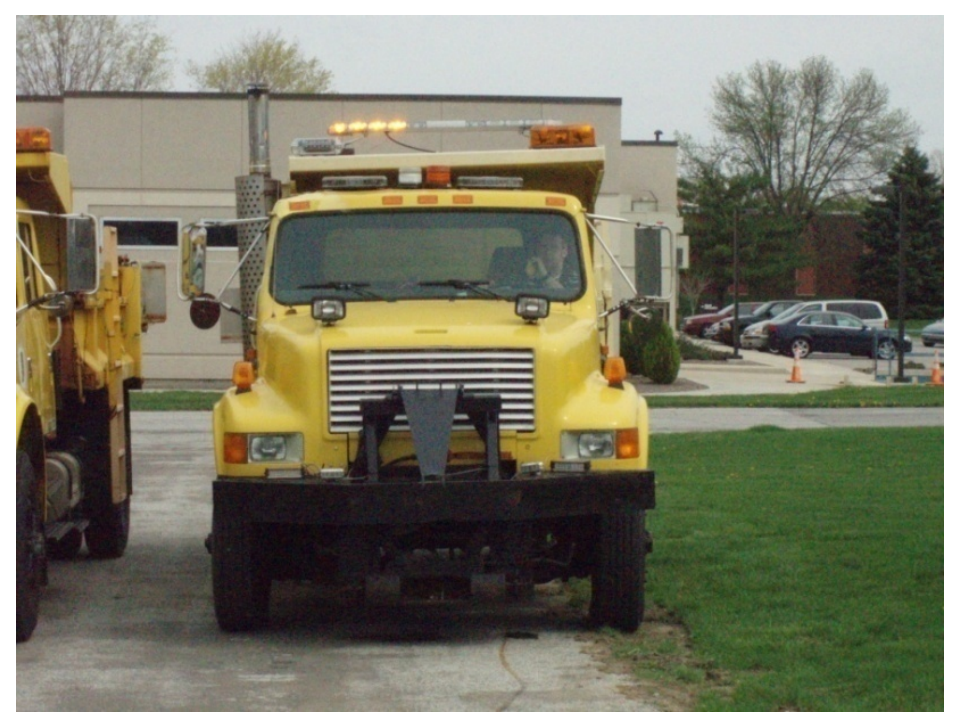

Figure 11- Soundoff Model ETL 5000 


\section{Beacons}

\begin{tabular}{|l|l|l|l|l|r|}
\hline 25 & 252651 & Amber & Strobe - Beacons & Soundoff & Magnetic mount \\
\hline 28 & $3207 \mathrm{Imc}$ & White & 3000 Beacon Light & Soundoff & \\
\hline 65 & $252653-03$ & Blue & Strobe - Beacon & Fed Sig & \\
\hline 66 & $252651-02$ & Amber & Strobe - Beacon & Fed Sig & Preferred \\
\hline
\end{tabular}

The one beacon or strobe preferred over the other was:

Federal Signal - 252651-02 Amber strobe.

Since beacons and light bars are located on the top of the truck cab they were compared against each other. These comparisons revealed that light bars are preferred over beacons.

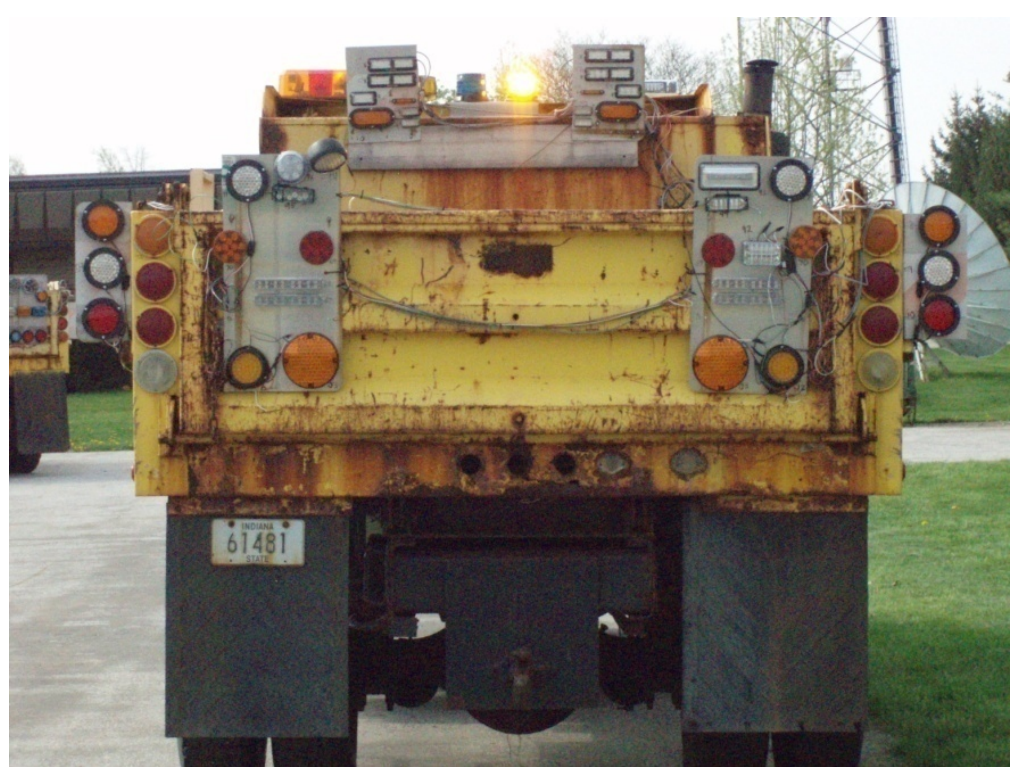

Figure 12 - Federal Signal 252651-02 Amber 


\section{Summary}

The state agencies described in this report used various lighting systems on their vehicles. Some are using LED lights which INDOT has not adopted yet. This study is recommending that INDOT rethink the use of LED lights. Other agencies are specifying and using this type of light. Light configurations vary among the agencies but commonalities exist like the use of strobes and a light bar. This study did not evaluate configurations so no recommendations are made.

The direct light observation was the methodology used to make the recommendations described in the previous section. These results have been compiled by using various observers and using the elimination process to perform comparisons. A major conclusion was that the LED lights were observed as brighter than others and very similar across all observation conditions. Also, in comparisons between the different light groups (round, surface, etc.), the LED lights were preferred.

One conclusion from the studies is that amber is the clear color preference across all color configurations. Amber was perceived by the observers as the brightest across all observation conditions. The second choice of color is bright blue. This is similar to color used by law enforcement vehicles and may be restricted. State law needs to be consulted.

Another factor to consider is size. Larger lights were observed to be more visible than smaller lights, even those smaller lights were brighter than the larger ones. These factors narrowed the field down to several lights. First, light 12(Amber), the ql64xfc-a quad flare, even with its partial burnout, was voted unanimously over the other lights tested against it. In the LED surface category there were three other lights recommended other than the ql64xfc-a.

The front of the truck is much easier to recommend due to the small number of lights typically used on this side of the truck. The lightbar, Light 36 (Soundoff - ETL5000) was the preferred one.

In conclusion, the results recommend INDOT to consider using these preferred light options. The preferences are based on visibility in various types of conditions, weather and lighting. Cost and arrangement of lights for INDOT vehicles are decisions that are to be made by Operations and the Districts.

The existing INDOT lights did not compare favorably with the recommended and preferred lights. Light choices are made by the Districts. The results from this study should be used by Operations and the Districts when making decisions on future light packages for INDOT equipment. 


\section{Implementation}

For the current fleet, as lights need to be replaced they should be replaced with the recommended lights. It is not feasible to mandate changing lights that are currently used on INDOT vehicles since they would require some retrofitting of the truck chassis. The INDOT committee that oversees the approval and purchasing of vehicle light packages needs to consider these results and realize that current lighting packages used by INDOT can be improved by using the recommended study lights and make INDOT vehicles more visible, thereby increasing safety for INDOT employees and the traveling public.

\section{References}

Bullough, J.D., Rea, M.S., et.al., Paper \#14: Rear Lighting Configurations for Winter Maintenance Vehicles, IESNA Annual Conference:Ottawa,ON, Canada, August 5-8, 2001.

Gibbons, Ronald B., NCHRP Project 13-02: Guidelines for Selection and Application of Warning Lights on Roadway-Operations Equipment, Transportation Research Board, National Research Council, Washington, DC, December 2006 - Number 624.

Kamyab, Ali and McDonald, Thomas J., "Synthesis of Best Practice for Increasing Protection and Visibility of Highway Maintenance Vehicles," Proceedings of the 2003 Mid-Continenet Transportation Research Symposium, Ames, lowa, August 2003.

Minnesota Department of Transportation, "Snow Plow Lighting Study," September , 1989.

Rea, Mark S., and Thompson, Brian E., NCHRP Project 6-12: Improved Visibility for Snowplowing Operations, Transportation Research Board, National Research Council, Washington, D.C., November 2000 - Number 250.

Ullman, Gerald and Lewis, Don, "Texas DOT Vehicle Fleet Warning Light Policy Research," Presentations from the $12^{\text {th }}$ Equipment Management Workshop.

Various phone conversations with DOT officials from: Minnesota, Georgia, Wisconsin, Nevada, South Dakota, Kansas, California, and Alaska. 